\title{
TRAUMA IN TANZANIA: Researching Injury in a Low-Resource Setting
}

\author{
Baijayanta Mukhopadhyay*, Respicious Boniface and Tarek Razek
}

\begin{abstract}
The prevalence of surgical trauma as a global public health hazard has been severely neglected. Trauma surgeons in Uganda and Canada have developed the Kampala Trauma Score (KTS), a trauma severity index specific to east African contexts. Hospitals in Tanzania have begun to use this tool to measure their own trauma management protocols in order to measure the validity of this index regionally. This study sought to enhance analysis of data collected through the KTS, by highlighting the efficacy and the lacunae of this registry through evaluation of the data quality of one ongoing round of data collection at an orthopaedic emergency room in Dar es Salaam, Tanzania. The data was screened for missing values that would have impact on prediction of clinical evolution and also analysed for contradictory evidence. Interviews were conducted with data collectors on the main challenges involved in data gathering and analysis for this project. Analysis of the initial round of data collection confirms road accidents cause the most trauma in Dar es Salaam, with pedestrians being particularly vulnerable. However, critical sources of information such as serious injury scores and two-week followup were inconsistently recorded, thereby limiting outcome measurement. The lack of research resources, both financial and human, had a major impact on the ability to sustain the data collection. While the results of this study demonstrate the public health value of having a mechanism to record trauma, research capacity must be supported in low-resource settings in order to enhance clinical care to accident and injury patients.
\end{abstract}

KEYWORDS: Surgery, trauma, global health, data quality, research capacity.

\section{INTRODUCTION}

The prevalence of surgical trauma as a public health hazard in low-resource settings globally has been severely neglected. Traditionally, surgery has been viewed as a resource-intense intervention that does not fit in with most effective public health models. However, surgery can provide solutions to diverse yet common crises such as appendicitis or obstructed labour, which constitute a large burden of global morbidity (1). Specifically, the World Health Organisation recognises accidents and injuries as a rising cause of disability and mortality globally (2).

*To whom correspondence should be addressed:

Baijayanta Mukhopadhyay

baijayanta.mukhopadhyay@mcgill.ca
Burns, road accidents and domestic violence are all common situations where surgical intervention may prevent death or disability (3). Of these, the focus on road accidents as a preventable cause of high mortality and disability has become central. Estimates go as high as 3000 people dying every day in road accidents worldwide. The very young, the very old, cyclists and pedestrians are the most vulnerable (4). As societies globally become more automated, increasing congestion of motor transport has made this issue of critical concern.

Understanding the burden injury that could otherwise be treated through simple trauma surgery places on global health systems cannot be accurately understood without effective means to monitor its prevalence. Furthermore, evaluating the capacity to respond to such a burden also requires effective management of data. As global capacity to provide emergency surgical care 
develops, mechanisms to monitor and evaluate outcomes also need to be instituted concomitantly. Trauma registries can improve surveillance to manage care, outcomes and prevention. Furthermore, using trauma scores to analyse injury data can identify best practices in treatment of injury by identifying where outcomes are improved (1). Some studies highlight the dangers that injury provides in resource-poor settings. However, many now aim to move beyond mere epidemiological analysis towards managing responses to such injuries.

Developing tools that permit appropriate monitoring and evaluation of burgeoning surgical capacity provides a means to ensure that challenges are identified, and successes are replicated, as demonstrated in Iran (5). This study showed that a standard trauma score, developed in North America, had some capacity to evaluate the care given to injury patients in the Iranian context, demonstrating where treatment of trauma there was suboptimal to comparative injuries in North America. A larger study, also in Iran, demonstrated that a registry system provides valuable information focusing attention on plausible public health intervention for injury prevention, specific to local contexts (6). Similar studies have been done in Costa Rica (7) and a study of occupational injuries from a government database of such incidents was completed in Turkey (8). In Nigeria, a retrospective study of data from hospital records focused on the specific issue of peripheral artery injuries to better understand prevention (9). These studies show how helpful a registry can be in diverse settings. However, correlating the epidemiological data of a registry with the clinical practice data from measurement of trauma severity scores requires a further step.

In North America, the Trauma Injury Severity Score (TRISS) is the standard tool used in hospitals to evaluate clinical performance in trauma wards. This score serves an outcome predictor. Using this standardised tool, comparisons of performance in order to identify problems or best practices are thus possible (10). However, TRISS can only be applied reliably in the settings where the index has been validated, in the high-resource settings of North America. Although there have been minor studies done to evaluate the adequacy of the scores in low-resource settings (5), more predictive efficacy could be reached by designing an index specific to low-resource settings.

Trauma surgeons in Uganda and Canada are already developing a trauma severity index specific to east African contexts (11). This index, the Kampala Trauma Score (KTS), was developed to be effective in areas where access to certain indicators may be costly or time-consuming. Thus, patient status is evaluated by taking four vital parameters into account: blood pressure, respiratory rate, neurological status and number of serious injuries sustained. These relatively easy measurements give a global overview of a patient's status, and in principle, can be correlated to the outcome of the case, given interventions appropriate for the patient's status.

The KTS has yet to be tested outside the centre in Uganda regionally. Analysis of data from Uganda showed some degree of success in predicting outcome, although evaluation of its efficacy as a triage tool remains to be seen (12). This data from Dar es Salaam, Tanzania is the first time data has been collected externally using this system of registry and trauma indexing. One round of data has already been evaluated from this collection in Dar es Salaam (13). The data presented in this round are the preliminary results from the second round of data being collected in Dar es Salaam, given the changes incorporated into the survey after the first round. Research is required to evaluate that data collection is standardised and consistent, in order to improve the ability to monitor and plan trauma management protocols specific to their context effectively (14). Regional reliability of trauma data has become an increasing concern in the field, even in the developed world, as populations become more mobile and social systems more integrated (15). Thus, testing the validity of this trauma severity registry is essential. Previous experiences in data collection from developing country registries have showed variable consistency in the recording of necessary data, requiring efforts to systematise the data available in manageable ways (1). The challenge is not insurmountable (13). However, research in the developing world faces serious difficulties in capacity (16). The transfer of research capacity from national systems to global actors is an issue, as well as the instability of political agendas to support research in low- and middle-income countries. Poor pay of research workers that require them to seek opportunities elsewhere also has an impact on research capacity in the developing world. Old models of academic partnerships in and of themselves have contributed to the degeneration of research capacity globally, as local authority has been pre-empted by external control of research agendas (17).

With this context in mind, this project thus sought to accomplish three primary goals: to understand the benefits maintaining a trauma registry can bring to the Tanzanian context, to describe the efficacy of the Kampala Trauma Score in monitoring injury in Dar es Salaam, and finally to evaluate the challenges apparent in the maintenance of such a registry for research purposes in this context. 


\section{METHODS}

The data analysed in this paper comes from an initial two-week collection of the second round of data from Tanzania. This round of data collection is derived from a survey instrument that has been modified to respond to collection challenges encountered in the year-long first round.

Some data in this round had to be dismissed as data collectors used the old tool for approximately twenty cases. The remaining data, involving 125 valid cases, was analysed for data quality concerns, screened for missing values and contradictory evidence. Interviews were also conducted with three project managers in the hospital administration to highlight some of the most pressing challenges in trauma registry maintenance. A focus group with emergency department nurses who served as data collectors at the Dar es Salaam site was also conducted. These data collectors were also responsible for clinical nursing duties for patients entering the emergency department, thus engaging in acute care to ensure stabilisation of patients' conditions.

\begin{tabular}{|l|r|r|}
\hline & Number of cases & Percent (\%) \\
\hline $\begin{array}{l}\text { Systolic blood pressure }>89 \\
\text { (score 2) }\end{array}$ & 113 & 90.4 \\
\hline $\begin{array}{l}\text { Systolic blood pressure 50-89 } \\
\text { (score 1) }\end{array}$ & 9 & 7.2 \\
\hline Blood pressure <50 (score 0) & 2 & 1.6 \\
\hline Blood pressure not recorded & $\mathbf{1}$ & $\mathbf{0 . 8}$ \\
\hline Total & 125 & 100 \\
\hline
\end{tabular}

Table I: Kampala Trauma Score - blood pressure ratings

\begin{tabular}{|l|r|r|}
\hline & Number of cases & Percent (\%) \\
\hline Respiratory rate 10-29 (score 2) & 114 & 91.2 \\
\hline Respiratory rate $>29($ score 1) & 11 & 8.8 \\
\hline Respiratory rate $<10$ (score 0) & 0 & 0 \\
\hline Respiratory rate not recorded & $\mathbf{0}$ & $\mathbf{0}$ \\
\hline Total & 125 & 100 \\
\hline
\end{tabular}

Table II: Kampala Trauma Score - respiratory rate ratings

\begin{tabular}{|l|r|r|}
\hline & Number of cases & Percent (\%) \\
\hline Alert (score 3) & 120 & 96 \\
\hline Response to verbal stimuli (score 2) & 2 & 1.6 \\
\hline Response to painful stimuli (score 1) & 1 & 0.8 \\
\hline No response (score 0) & 2 & 1.6 \\
\hline Neurological status not recorded & $\mathbf{0}$ & $\mathbf{0}$ \\
\hline Total & 125 & 100 \\
\hline
\end{tabular}

Table III: Kampala Trauma Score - neurological rating
Therefore, it is important to note that they were not primarily researchers steeped in the research questions and methodology, their main interest being to ensure appropriate care of the injured patient. While the data they recorded would be pertinent to routine care, the burden of filling out additional paperwork could come into conflict with their clinical duties. The data collectors were however remunerated a nominal amount for every score evaluation conducted.

A visit to a rural clinic at Mkuranga, $80 \mathrm{~km}$ outside of Dar es Salaam, where data collection has commenced as part of a national process, provided additional information on the nature of trauma registries in Tanzania, through interviewing the project coordinator at that site.

\section{RESULTS}

Basic demographic data was generally simple to collect. Initial findings from the second round of data confirms the general understanding that men are preponderantly susceptible to visit the emergency room, involving 97 cases of the 125.19 cases of those studied were minors, aged 17 or less. There were some inconsistencies in recording of age, as some collectors recorded year of birth rather than age. In three cases, simply « adult » was noted, and in four cases, age was not recorded at all. Of anecdotal interest, on the initial day of the visiting researcher's stay at the hospital, all four beds in the department devoted to serious injuries were occupied by young men (suffering head trauma from road accidents).

Certain parameters required to define the trauma score on the Kampala scale did not pose problems. The vast majority of cases came in with normal systolic blood pressure, and this index was not scored in only one instance (see Table I). Eleven cases came in with poor respiratory rates, five of which were children, one unknown. Of all cases, 120 showed no neurological symptoms. Two cases showed the poorest neurological signs of no response to any stimuli whatsoever, one of those cases being a child.

Concerns about data quality begin to emerge when measuring the seriousness of injuries. Although in interview, collectors seemed clear about what constituted a serious injury - anything that required surgical intervention - there seemed to be inconsistencies within datasets about which injuries were counted. These discrepancies came to light as there was a repeated question on serious injury. One question, question 9, asked the collector identify the number of serious injuries. Another question, question 19 , asked the clinician to identify the site of serious injuries. Table IV shows some of the findings of this internal cross-checking, with figures of note in bold. 
The table compares the initial reporting of serious injury of the case under question 9 by the data collector, against where they later record as the site of serious injury under question 19. For instance, of the 47 patients who were initially described as having no serious injuries, 8 were later noted to have the head/neck as a site of serious injury, and 26 at the pelvis or extremities. Of the 55 who were initially noted to have one site of serious injury, 1 was later described as having no site of serious injury, 3 as multiple sites of injury and 9 had no site recorded at all.

This inconsistency in data collection must naturally lead to inaccuracies in calculating the total KTS. These problems were compounded by simpler errors, where, for example, clinicians provided a total score for four of the twelve cases which had not been scored on the serious injury scale. The KTS was not calculated in eight cases but can be extrapolated from the component scores, all of them at a stable 8 . In four cases where there was no serious injury score, the data collector nonetheless provided a KTS score, all of them a stable 8.

Besides the problems with actual scoring, there were other points to note on the data collection (see table V). In three cases of the total, the cause of the injury was unknown. Otherwise, 58 cases were caused by road accidents, 39 were caused by a fall, two were stabs or cuts, two were blunt force and 21 were from other causes. However, when prompted, 14 of the cases in this latter category were described as assaults, rather than by the specific nature of the assault described in the earlier categories.

Given the preponderance of road accidents, the survey asked for further detail regarding the circumstances of these injuries (see table VI). Of the 58 road accidents, the highest proportion was those involving vehicles and pedestrians as counterparts -31 out of the 55 of the cases where the counterparts were noted by data collectors in the survey. Almost exclusively, the injured party in these cases was the pedestrian. Important information regarding seatbelt use (or helmet use in the case of motorcycle or bicycle accidents) was quite well recorded where relevant (see table VII). Gathering this data is essential to enhance monitoring and implementation of public health initiatives.

Patient disposition was generally adequately noted, with only four cases missing data. The most critical lack of information comes from the two-week followup (see table VIII). Of the 125 cases, only 31 had information on the follow-up, of which 22 remained discharged, two had died and the remainder were still noted as remaining in hospital. Of the 39 cases originally noted as having been admitted to the hospital, two-week follow-up was missing for 30 of them. Interestingly, of the two who died, one had no KTS score noted and the other had come in scored as a stable 9.

\section{DISCUSSION}

The results of the study bring to the forefront three major overarching issues.

\section{The Epidemiology of Injury}

Firstly, the ability to monitor data in an emergency department provides valuable insight into the nature of injuries that are prevalent in an area. As such, registries may prove to be an effective tool for public health interventions, in their capacity to direct resources towards addressing the most serious concerns in preventing accident and injury. The data, although preliminary, provides an overview of the injuries that

\begin{tabular}{|c|c|c|c|c|c|c|c|c|c|c|}
\hline \multirow{3}{*}{\begin{tabular}{|c|} 
\\
Answer \\
provided to \\
question 9 \\
as to \\
number of \\
serious \\
injuries in \\
patient
\end{tabular}} & & \multicolumn{9}{|c|}{ Answer provided to question 19 as to site of serious injury or injuries. } \\
\hline & & $\begin{array}{c}\text { No site of } \\
\text { serious } \\
\text { injury }\end{array}$ & $\begin{array}{c}\text { Head/ neck/ } \\
\text { face }\end{array}$ & Chest & Spinal cord & $\begin{array}{l}\text { Abdomen, } \\
\text { pelvis and } \\
\text { perineum }\end{array}$ & $\begin{array}{l}\text { Bony pelvis } \\
\text { and } \\
\text { extremities }\end{array}$ & $\begin{array}{c}\text { Multiple } \\
\text { sites of } \\
\text { serious } \\
\text { injury }\end{array}$ & $\begin{array}{c}\text { Site not } \\
\text { recorded }\end{array}$ & Total \\
\hline & $\begin{array}{c}\text { No serious } \\
\text { injury }\end{array}$ & 12 & 8 & 0 & 0 & 0 & 26 & 0 & 1 & 47 \\
\hline & $\begin{array}{c}\text { One serious } \\
\text { injury }\end{array}$ & 1 & 13 & $\overline{0}$ & 0 & 1 & 28 & 3 & 9 & 55 \\
\hline & $\begin{array}{l}\text { Two or } \\
\text { more } \\
\text { serious } \\
\text { injuries }\end{array}$ & 0 & 4 & $\overline{0}$ & 0 & 1 & 6 & 0 & 0 & 11 \\
\hline & $\begin{array}{c}\text { Number not } \\
\text { recorded }\end{array}$ & 0 & $\overline{2}$ & $\overline{0}$ & $\overline{0}$ & $\overline{0}$ & 6 & 0 & 4 & 12 \\
\hline & Total & 13 & 27 & 0 & 0 & 2 & 66 & 3 & 14 & 125 \\
\hline
\end{tabular}

Table IV: Comparison of responses to Questions 9 and 19. Initial Kampala Trauma score rating for serious injury vs. later identification of site of serious injury 


\begin{tabular}{|l|c|c|}
\hline & Cases & Percent (\%) \\
\hline Road accident & 58 & 46.4 \\
\hline Fall & 39 & 31.2 \\
\hline Stab/cut & 2 & 1.6 \\
\hline Blunt force & 2 & 1.6 \\
\hline $\begin{array}{l}\text { Gunshot/poison/bite/choking/sexual } \\
\text { assault/drowning/landmine/bomb/burn }\end{array}$ & 0 & 0 \\
\hline Other & 21 & 16.8 \\
\hline Cause not recorded & 3 & 2.4 \\
\hline Total & 125 & 100 \\
\hline
\end{tabular}

Table V: Causes of injury

place the most burden on an orthopaedic emergency room in Dar es Salaam. Clearly, mimicking global trends, road accidents are a major concern in the region. Pedestrians appear the most vulnerable in this particular context. There is also particular concern for the health status of young men. While this statistic may be due to the enhanced risk-taking behaviours of men, it is also plausible that women in Dar es Salaam are less likely to seek formal care for injuries than men, thus presenting less often to the emergency room. This question needs further exploration.

\section{The Power of Evidence}

Secondly, the leverage tool the registry provides in order to launch public health interventions underscores its importance. This data can be used both by national authorities in Tanzania, as well as regionally and more globally, to address pressing issues of road safety and accident awareness. Although human resources are insufficient to devote to this work, the interviews with hospital administration in Dar es Salaam underlined the necessity of bringing this data to government authorities to launch a campaign to limit the injury burden from road accidents.

\section{The Challenges of Capacity}

Thirdly, the process of launching and maintaining the registry at a national hospital in a low-resource setting promotes the development of capacity to engage in research in these contexts, which is direly needed in order to make sure public health dollars are spent effectively. Locally-led research ensures that funds are not misdirected to concerns that are externally determined. While these initiatives bring to light global health concerns that need redress, they also enhance global health equity in acknowledging the expertise of researchers active in low-resource settings. The hospital administration in Dar es Salaam shows remarkable commitment to the research process with little public support, fuelled by the energy of a few individuals. Recognising the contributions their work has made to global health is also critical.

Overall, the relative completeness of the components of the Kampala Trauma Score collection shows that at least the three initial parameters (blood pressure, respiratory rate, and neurological status) are efficient indicators to collect data in clinical contexts in Tanzania. Whether they adequately describe patient outcomes remains to be seen, although the analysis done on the more extensive Ugandan data suggests that as the Tanzanian data is more rigorously collected and

\begin{tabular}{|c|c|c|c|c|c|c|c|c|}
\hline & Vehicle driver & $\begin{array}{c}\text { Vehicle } \\
\text { passenger }\end{array}$ & Pedestrian & Motorcyclist & $\begin{array}{l}\text { Motorcycle } \\
\text { passenger }\end{array}$ & Bicyclist & $\begin{array}{l}\text { Injured party not } \\
\text { recorded }\end{array}$ & Total \\
\hline Vehicle-vehicle & 2 & 10 & 0 & 0 & 0 & 0 & 1 & 13 \\
\hline $\begin{array}{c}\text { Vehicle- } \\
\text { motorcycle }\end{array}$ & 0 & 0 & 0 & 5 & 0 & 0 & 0 & 5 \\
\hline Vehicle-bicycle & $\overline{0}$ & 0 & 0 & 0 & 0 & 2 & $\overline{0}$ & 2 \\
\hline $\begin{array}{c}\text { Vehicle- } \\
\text { pedestrian }\end{array}$ & $\overline{0}$ & $\overline{0}$ & 29 & $\overline{0}$ & $\overline{0}$ & $\overline{0}$ & 2 & 31 \\
\hline $\begin{array}{c}\text { Motorcycle- } \\
\text { motorcycle }\end{array}$ & 0 & 0 & 0 & 0 & 1 & 0 & 0 & 1 \\
\hline $\begin{array}{l}\text { Motorcycle- } \\
\text { bicycle }\end{array}$ & 0 & 0 & 0 & 0 & 0 & 0 & 1 & 1 \\
\hline $\begin{array}{l}\text { Motorcycle- } \\
\text { pedestrian }\end{array}$ & 0 & 0 & 0 & 2 & 0 & 0 & 0 & 2 \\
\hline $\begin{array}{l}\text { Counterparts not } \\
\text { recorded }\end{array}$ & $\overline{0}$ & 2 & $\overline{0}$ & $\overline{0}$ & 1 & $\overline{0}$ & 0 & 3 \\
\hline Total & 2 & $\overline{12}$ & 29 & 7 & 2 & 2 & 4 & 58 \\
\hline
\end{tabular}

Table VI: Road accidents - counterparts involved and injured party 
analysed, there will be predictive capacity (12). However, the results for the serious injury score in this preliminary Tanzanian data, for example, show some of the most pressing concerns in data collection.

The interviews provided some nuance to the questions where the most critical lapses occurred. The project managers noted that inadequate support for research capacity requires that nurses undertake the work. The nurses in the emergency room, in return, underlined that balancing the needs of the researcher and clinician in a busy emergency room was difficult, with the research needs suffering. This reality was particularly highlighted at the rural clinic, where the data entries (not analysed here) were much more nuanced and detailed, given the many fewer visits at Mkuranga.

While some of the difficulties could be ascribed to the fact that this data collection occurred early on in the round of data collection, it must be noted that the hospital had conducted one full year's round of data collection previously. Introducing new data collectors to the process can naturally cause difficulties, but providing immediate feedback once these challenges have been identified early on is necessary to ensure usable data arises in the long-term. In the meantime, a stopgap measure of cross-checking data with hospital records themselves may be instituted. However, devoting human resources to this task is also an untenable drain on clinical work in the hospital.

For future perspectives, the two most important areas where further improvement of data collection needs to take place are in scoring serious injury, and in recording outcomes in the two-week follow-up. Adequate recording of this component is essential, as an accurate calculation of the KTS is dependent on it. The former can be a challenge given the possibilities of rapid clinical evolution in emergency settings. However, refining the design of the survey in this regard may

\begin{tabular}{|c|c|c|c|c|}
\hline & Used & Not used & $\begin{array}{c}\text { Data not } \\
\text { recorded }\end{array}$ & Total \\
\hline $\begin{array}{c}\text { Vehicle } \\
\text { driver }\end{array}$ & 0 & 2 & 0 & 2 \\
\hline $\begin{array}{c}\text { Vehicle } \\
\text { passenger }\end{array}$ & 0 & 12 & 0 & 12 \\
\hline Motorcyclist & 3 & 3 & 1 & 7 \\
\hline $\begin{array}{c}\text { Motorcycle } \\
\text { passenger }\end{array}$ & 0 & 1 & 1 & 2 \\
\hline Bicyclist & 0 & 2 & 0 & 2 \\
\hline Unknown & 1 & 0 & 0 & 1 \\
\hline Total & 4 & 20 & 2 & 26 \\
\hline
\end{tabular}

Table VII: Data on protection used by road user - seatbelt/helmet prove useful, requiring clinicians to list only the sites where intervention was required. The data analysers can then total up this elementary information to assign a serious injury score themselves, ensuring that there is no repetition of the same data in the collection. In this way, the analysers can also do the work of calculating the total KTS, further relieving the burden from the data collectors so they are required only to gather the most elementary components of the data. Furthermore, clear definitions of what constitutes a serious injury need to be refined further, taking into account that surgical intervention alone cannot be the most reliable marker of gravity of trauma. It is conceivable that there is not even a consensus amongst data collectors on what constitutes a surgical intervention itself.

Sustaining the collection of outcome data is critical to harness the entire potential of a trauma registry, in order to monitor the effectiveness of treatment in each setting. In this consideration, the lack of capacity to undertake a two-week follow-up, even as minimally required by this survey instrument, was limited with the resources available to the hospital. Even though most data collected by the survey instrument was also independently entered into the hospital records, there was little time to cross-check this data with hospital records, and certainly two-week follow-up was often impossible by the emergency nurses even if the patient remained in hospital. Rather than research design, this problem is a more structural issue in low-resource settings of limited research capacity.

Clearly, addressing this difficulty cannot be resolved within one project alone. In the long-term, the registry would ideally be integrated into routine care in the emergency department across east Africa, perhaps incorporated into regular charting activities in order to monitor the predicted outcomes and the course of treatment of trauma patients. However, much needs to be done to verify the validity of the tool until then. The

\begin{tabular}{|c|c|c|c|c|}
\hline & $\begin{array}{c}\text { Patient } \\
\text { discharged }\end{array}$ & $\begin{array}{c}\text { Patient } \\
\text { admitted }\end{array}$ & Unknown & Total \\
\hline $\begin{array}{c}\text { Patient } \\
\text { discharged } \\
\text { within two weeks }\end{array}$ & 22 & 0 & 0 & 22 \\
\hline $\begin{array}{c}\text { Patient died } \\
\text { within two weeks }\end{array}$ & 0 & 2 & 0 & 2 \\
\hline $\begin{array}{c}\text { Patient still in } \\
\text { hospital at two } \\
\text { weeks }\end{array}$ & 0 & 7 & 0 & 7 \\
\hline $\begin{array}{c}\text { Two-week status } \\
\text { unknown }\end{array}$ & 60 & 30 & 4 & 94 \\
\hline Total & 82 & 39 & 4 & 125 \\
\hline
\end{tabular}

Table VIII: Outcomes follow-up 
establishment of research partnerships between highresource settings and lower-resource contexts can be helpful, only if there is a transfer of both financial and human resources to local actors so that research capacity within the society is enhanced. Control of research agendas and projects needs also to remain within the developing world.

\section{CONCLUSION}

The current process of data collection in Tanzania provides very interesting descriptive data on the nature of injury in a particular setting, which provides evidence upon which to build public health interventions. However, to improve clinical outcomes, further refinements in the data collection process need to be instituted through modifications to the survey tool, and particularly, further resource allocation to bolster clinical research capacity in emergency rooms in the country. Once this capacity to monitor outcomes is developed, further research into the correlation of patient status and outcome, depending on interventions used, needs to be undertaken in order to develop an analysis of the clinical capacity to respond to trauma in this context. The ultimate goal is, after all, to refine practice to improve patient outcome. Especially given the increasingly high burden injuries are placing on global health systems given the advent of motorised traffic worldwide, this work is becoming imperative to protect those most vulnerable to these accidents. However, the process requires a solid base of evidence upon which to design both treatment and prevention interventions. These challenges cannot be overcome unless there is serious investment in clinical research in low- and middle-income countries.

\section{ACKNOWLEDGEMENTS}

This project was supported by the McGill Summer Research Bursary Program.

\section{REFERENCES}

1. Bickler SW. Rode H. Surgical services for children in developing countries. Bulletin of the World Health Organization. 80(10):829-35, 2002.

2. World Health Organisation. Report: WHO Meeting towards a Global Initiative in Emergency and Essential Surgical Care. Available at: http://www.who.int/surgery/mission/GIEES C2005_Report.pdf. Last accessed: 3 March 2008.
3. Schultz CR. Ford HR. Cassidy LD. Shultz BL. Blanc C. KingSchultz LW et al. Development of a hospital-based trauma registry in Haiti: an approach for improving injury surveillance in developing and resource-poor settings. Journal of TraumaInjury Infection \& Critical Care. 63(5):1143-54, 2007 Nov.

4. World Health Organisation. Road traffic injuries. http://www.who.int/violence_injury_prevention/road_traffic/en/ Last accessed 2 March 2009.

5. Chardoli M. Rahimi-Movaghar V. Analysis of trauma outcome at a university hospital in Zahedan, Iran using the TRISS method, East African Medical Journal. 83(8):440-2, 2006 Aug.

6. Roudsari BS. Shadman M. Ghodsi M. Childhood trauma fatality and resource allocation in injury control programs in a developing country. BMC Public Health. 6:117, 2006

7. Buchanan S. Krantz A. Klempner S. Alvarado R. Wesseling C. Fernandez E. Forst L. Use of a national reporting system for occupational injuries in Costa Rica. International Journal of Occupational \& Environmental Health. 12(2):142-6, 2006 AprJun.

8. Etiler N. Colak B. Bicer U. Barut N. Fatal occupational injuries among workers in Kocaeli, Turkey, 1990-1999. International Journal of Occupational \& Environmental Health. 10(1):55-62, 2004 Jan-Mar.

9. Thomas MO. Giwa SO. Adekoya-Cole TO. Arterial injuries in civilian practice in Lagos, Nigeria. Nigerian Journal of Clinical Practice. 8(2):65-8, 2005 Dec.

10. McKenzie K. Walker S. Besenyei A. Aitken LM. Allison B. Assessing the concordance of trauma registry data and hospital records. Health Information Management Journal. 34(1): 3-7, 2005.

11. Kobusingye OC. Lett RR. Hospital-based trauma registries in Uganda. Journal of Trauma-Injury Infection \& Critical Care. 48(3):498-502, 2000 Mar.

12. MacLeod JBA. Kobusingye O. Frost C. Lett R. Kirya F. Shulman C. A comparison of the Kampala Trauma Score (KTS) with the Revised Trauma Score (RTS), Injury Severity Score (ISS) and the TRISS Method in a Ugandan trauma registry. 29(6):392-398, 2003 Dec.

13. Museru L. Leshabari M. Boniface R. Munthali V. Lett R. Pattern of injuries in the orthopedic and trauma national referral hospital: need for injury prevention strategies in Tanzania. [Unpublished, forthcoming.]

14. Datta I. Findlay C. Kortbeek JB. Hameed SM. Evaluation of a regional trauma registry. Canadian Journal of Surgery. 50(3):210-3, 2007 Jun.

15. EuroTARN Writing Committee on behalf of the EuroTARN Group. A comparison of European Trauma Registries. The first report from the EuroTARN Group. Resuscitation. 75(2):286-97, 2007 Nov.

16. Sitthi-amorn C. Somrongthong R. Strengthening health research capacity in developing countries: a critical element for achieving health equity. BMJ. 321: 813-817, 2000 Sep.

17. Costello A. Zumla A. Moving to research partnerships in developing countries. BMJ. 321: (827-829), 2000 Sep.

Baijayanta Mukhopadhyay is a medical student at McGill University, Montreal, Canada.

Respicious Boniface is an anaesthesiologist at Muhimbili Orthopaedic Institute in Dar es Salaam, Tanzania, and is also the director of the Injury Control Centre-Tanzania.

Tarek Razek is the Chief of Trauma Surgery at the McGill University Health Centre in Montreal, Canada 